\title{
Deryck M. Schreuder, ed. \\ Universities for a New World: Making a Global Network in International Higher Education, 1913-2013
}

New Delhi:The Association of Commonwealth Universities and SAGE Publications, 2013. 425 pp.

\section{Roopa Desai Trilokekar}

York University

The title of this book is fitting. It is a book about reflecting back on a time when the "oldest [international] higher education network in modern history" (xxvii), the Association of Commonwealth Universities (ACU), supported the development of "new" universities in the United Kingdom, its dominions, and its colonies. But it is also about looking forward at the challenges of maintaining the relevance of this historical network in a new, twenty-first century geopolitical era and context of "new international universities." This book is unique compared to earlier, celebratory historical accounts of the ACU. ${ }^{1}$ The twenty-five essays in Universities for a New World, by international educationalists and scholars who presented at a London Symposium marking the ACU's centenary, provide a broad discussion on university transformations and challenges, including, but not specific to the Commonwealth. The book makes a rich and insightful contribution as it taps into the legacy of ACU's 500 institutional members across more than 50 countries, thus providing a historical perspective to the full spectrum of global higher education provision.

The book includes a personal welcome and foreword by two Commonwealth stalwarts, Thomas H.B. Symons, founding President and Vanier Professor Emeritus, Trent University, Canada, who was instrumental in designing the Commonwealth Scholarship and Fellowship Plan, and E. Nigel Harris, Chair ACU Council and Vice-Chancellor, University of the West Indies (UWI), from a unique and influential regional institution with origins in the British Empire. In his introduction, editor Deryck Schreuder provides a historical account of the losses and gains from the many transformations in the purpose, organization, and approaches of the university - reminding us of the continued relevance of John Henry Newman's treatise, The Idea of 
University, a theme revisited by several authors in this book. In particular, Schreuder succeeds in addressing the complexity with which "the age of tradition and certainties on campuses under threat, ... also [become] the source of transformation and growth" (xi). He succeeds as well in highlighting changed geopolitics that have realigned international relations and the meaning and purposes of international higher education, while bringing forth new networks and forms of cooperation. Schreuder's insights are fundamental to recurring questions the book raises: What is the future role of universities? What are the values? Is the Commonwealth of continued salience as an international network in this future world?

The book is divided into four parts. Each one includes a useful introductory prelude setting the context and offering a wide range of thematic and regional bibliographic references, websites, and lists of programs and networks. Part I: History: Network and the "New World" (4 chapters) provides an interesting account of ACU from its inception to changes in its relationships to the Commonwealth. This part of the book highlights the University of London's crucial role in the "veritable making of new universities in the new world" (28). Part II: Transformations: Instruments and Symbols of Change in Higher Education (5 chapters) highlights the "major driving forces that have animated the academic revolution globally" (87), focusing on e-learning, gender equity, quality, student mobility, and changed policy priorities that have decreased the power of the Commonwealth as a "political catch phrase" (194). Part III: Impact: Regional Case Studies in Access, Equity and Social change ( 4 chapters) complements the earlier chapters with selected case studies of national types (African nations; Asia: India and Pakistan; Australia; and the small countries of the English-speaking Caribbean). It provides an excellent history of the complexity and regional scale of challenges in higher education. Part IV: Prospect: University Futures (3 Chapters) proposes "a regime change" (331), going from basic science to strategic science, "a harbinger of [a transformed institutional form] the post modern university" (344). Other changes are proposed as well, stemming from the digital revolution, globalization, and government actions, and are intended to result in a progressive fragmentation of institutions and subsequent erosion of their traditional values. The book concludes that the greatest challenge for the ACU is to consider "a new renaissance" (383), a "reinvention" (328) of the notion of the university by making a resolute commitment to change and constant development under "principled and firm leadership, [from] those who do not cling to every form of the past for fear of the future" (372).

The book, as a challenge or critique, encourages a paradigm shift in our thinking on the future role of the university, while retaining at heart its core values and character. However, a question arises. Are the authors subscribing to the very discourses the book sets out to critique? One example of this can be found in Chapter 10 where the author notes: "only two African institutions are featured in The Times Higher Education ranking of 200 universities across the globe - an indication that the region has not made as much progress as it should have, given its resources" (233) and assesses Africa as the least developed continent by international university ranking standards. Another example is from Chapter 11, where the author emphatically 
states that both "India and Pakistan must have some world class research universities" (280). Inclusiveness and representation of the ACU Southern members seemingly is highly valued, yet shortcomings exist in recognizing and promoting Southern case studies. For example, the UWI is recognized for its contribution to building scholarship relevant to the Caribbean and the developing world. Yet no parallels are drawn for lessons that can be learnt from the successful UWI case for African initiatives that have made only marginal progress in furthering the relevance of their universities in promoting African culture, practices, and unity. Similarly with growing interest in the establishment of regional universities, it is surprising that UWI's success is not more prominently highlighted. The book acknowledges the centrality of universities as knowledge producers; however given the colonial history of both the university and the Commonwealth, it is indeed surprising that it does not offer a critique of the notion of knowledge and knowledge production from a post-colonial and postmodern lens. The extremely brief and cursory discussion on pre-colonial academic traditions in Africa and Asia especially in context of current challenges and transformations of the university is troubling.

This book offers an interesting story in higher education transformation; its particular contribution is the rich and diverse examples of regions, nations, institutions, and programs as "samplers" in the case for global education transformation. In moving forward the accumulated experience and expertise of this oldest international network, the ACU, two suggestions offered are worth highlighting: that the Commonwealth support scholarships to mobilize international research teams to address selected issues of Commonwealth concern and that it support educational programmes for teaching and research about the Commonwealth itself.

\section{Notes}

1 Eric Ashby, Community of Universities: An Informal Portrait of the Association of Universities of the British Commonwealth, 1913-1963 (Cambridge: University Press, 1963) and Hugh W. Springer, with Alastair Niven, The Commonwealth of Universities: The Story of the Association of Commonwealth Universities, 1963-1988 (London: ACU, 1988). 